There is little need of comment upon Fischer's classification of scales of coleoptera into conchiform scales (Muschelschuppen), metallic scales (Metalblattschuppen), granulated scales (Granulationsschuppen), piliferous and shaggy scales (Haar- und Zottenschuppen) and fibrous scales (Faserschuppen). Leydig, as quoted above, destroyed the value of the division of granulated scales, and I have found that the division of fibrous scales owes its origin to what Fischer would call "granulations," that is to air-spaces, only that, in this case the granulations are arranged longitudinally in stripes. I can present no new classification of scales, if such a classification is possible, without studying more forms.

Before concluding this paper I will add a note on the mode which I have employed to gather scales, and some other minute objects of like nature, together upon one place on a microscope slide. The process consists in putting the scales in a drop of some quickly evaporating substance-chloroform is best for most purposes - on the slides. The scales will form in a kind of whirlpool, nearly all the scales finally settling down, as the liquid evaporates, in one place on the slide. Rapping the slide gently sometimes aids in the collecting together of the scales, and the tip of the scalpel used to scrape the scales from the insect can be washed in the drop of chloriform, thus saving every scale when they are from a rare specimen from which one desires to remove only a few scales. By inclining the slide gently, the mass of floating scales can be made to settle on the exact centre of the glass. One part of Canada balsam added to several hundred parts of chloroform will cause the scales to stick firmly to the slide.

( $T$ o be continued by a notice of some literature seen since preparing the original paper.)

\title{
THE CLASSIFICATION OF THE TINEIDAE.
}

BY VACTOR TOUSEY CHAMBERS, COVINGTON, KY.

My attention has just been called to an article by $\mathrm{Mr}$. Grote in Papilio, vol. 3. On page 43 he writes "I do not wish to enter into an argument as to the best classification of the tineidae, but disagreeing with $\mathrm{Mr}$. Chambers, I do not think any one would take Anaphora for any thing but a tineid ;" and on page $3^{8}$ he writes, "So far as I have studied them we appear to be able to classify our moths under sphingidae-tineidae", \&c., \&c., naming the families usually adopted. I refer to this subject because the first of these above-quoted passages conveys the impression that I have stated that Anaphora ought to be placed elsewhere than in tineidae, and because the second quotation gives me an opportunity to write more fully than I have elsewhere done as to the classification of the tineidae; an opportunity that I desire because two such distinguished entomologists as Lord Walsingham and Mr. Grote have, very courteously of course, taken me to task for the expression of opinions as to the classification of the tineidae which are by them considered more or less 
heterodox. I am not aware that I have anywhere expressed such an opinion as is by implication at least attributed to me in the above quotation as to the position of Anaphora. Mr. Grote was, I suppose, thinking of some remarks by me in an article in a previous number of Papilio, which was written in response to one by Lord Walsingham. His Lordship had stated that "It is surely easier at first sight to separate these [tineid] genera from those of other families" \&c., than to locate or separate certain other genera of those other families, thus seeming to convey the idea that there is a something, je ne sais quoi, about the tineid genera referred to by him which made it comparatively easy, "at first sight," to refer them to the tineidae; and if $\mathrm{Mr}$. Grote will look at my paper in Papili a little more carefully he will see that my remarks upon Anaphora hinge upon the words of Lord Walsingham, "at first sight ;" and that while I do not deny the tineid affinities of Anaphora I was unable to see with Lord Walsingham this indefinable and to me inappreciable something which makes the location of the tineid genera among the tineidae easy "at first sight" as compared with the genera of other families mentioned by his Lordship; and I instanced Anaphora as a tineid genus which at first sight - by one who was unacquainted with it - was more likely to be referred to the noctuidae than to the tineida. And I am yet of that opinion. There is something in the size, form, and color, especially of the darker species of Anaphora, that "at first sight" is much more suggestive of the noctuidae than it is even of the true tineidae, to which examination shows that it belongs: and if there is anything about Anaphora that "at first sight," or "second sight" either, shows it to belong to any other section of tineidae than that which contains Tinea proper, I don't know what it is. If there is anything under the sun about Anaphora, or for that matter about a true Tinea, say $T$. tapetzella, which at first sight, or upon the most careful examination, suggests that it is more closely allied to Gracilaria, Lithocolletis, Gelechia, Cemiostoma, or any of the host of smaller tineidae than it is to Noctua, I have failed to detect it, and if no resource was left to me but to either place Anaphora in noctuidae, or in the same family with Phyllocnistis or any of the genera of smaller moths known to me, then I should unhesitatingly refer Anaphora to the noctuidae. Anaphora no doubt belongs to the tineidae, restricted to the allies of Tinea by Mr. Stainton in his Insecta Britannica, v. 3, but neither Lord Walsingham nor $\mathrm{Mr}$. Grote uses the name tineidae in this sense in the papers above quoted. Both, in the papers in Papilio above mentioned, have discarded even Stephens' distinction between tineidae and hyponomeutidae, and include under the name tineidae all or nearly all of the genera included by Stephens in both of his families, with some others not mentioned by him, thus placing Cemiostoma, Nepticula, Tischeria, Phyllocnistis, Aspidisca, Heliodines, Lithocolletis, Gracilaria, 
Gelechia, and a host of other genera, so numerous that time fails me to mention them, possessing among themselves the most varied structure and metamorphoses, along-side of Anaphora, Tinea, Exapate Ochsenheimeria, \&c., as genera of equal value in the same family, the tineidae!

Lord Walsingham does indeed, in Papilio, refer to certain sub-groups of the family tineidae, but still he evidently considers them minor groups and looks upon the tineidae as a homogeneous group or family in the same sense with noctuidae or geometridae. To $\mathrm{my}$ view it (the tineidae of these authors) is about as heterogeneous a group of moths as that would be which should contain the bombycidae, noctuidae, geometridae, tortricidae and pyralidae thrown into one: the species or genera conuprised in it have no unity of structure, habit, metamorphosis, life-history, habitat, or ornamentation, and a family which comprises the genera referred to above (and others equally heterogeneous) might just as consistently contain all lepidoptera heterocera at once : it would then scarcely be more mixed that it is now. I don't like to dissent from such able and distinguished entomologists as Lord Walsingham and Mr. Grote, but truth is better even than good company.

I have stated elsewhere that I thought Stephens' classification of the tineidae thoroughly vicious. This language is too strong. I will say rather that I think his classification radically bad in so much as it gives too much weight to the presence of both pairs of palpi, and their size - it is too much a palpal classification - not consistently carried out, and one which it seems to me im- possible to carry out consistently. Still it was a step in the right direction, and infinitely better than the arrangement which places all of the genera known to Stephens and many others in a single family. The objection to Stephens' arrangement is that it does not recognise families enough, and my objection to Mr. Stainton's classification is that it recognises perhaps too many. Mr. Stainton's tineidae (restricted) seems to be a good and natural family of equal or nearly equal value with the noctuidae, but his gracilaridae and lithoculletidae, together with Phyllocnistis, instead of forming two families and part of a third, form together a single, well defined family. The structure and metamorphoses of the larvae and pupae seem to me to separate these moths from all of the known tineidae, and to unite them in a single natural group having family characters more than usually well marked. Whether the structure of their larvae and pupae are the result of evolution from some lower form, or of degradation from some higher one, that evolution or degradation has evidently been along the same lines in all of the genera included in the group, and shows a near relationship between them as well as a different development from anything that is known elsewhere among lepidoptera: for the course of development from the egg to the imago is different entirely from that of all the other groups of the order, and the eggs themselves are of different shape, size and consistency from those of all the other small moths known to me. They form, therefore, in my opinion, a family at least as dis- 
tinct and well limited as the true tineidae or even more so. The nepticulidae seem to me to form another natural family. The immense host comprised in Mr. Stainton's families hyponomeutidae, gelechidae, glyphipterygidae, coleophoridae, form at least one other family, if not more than one, though I incline to include the last three, at all events, in a single family. A large number of genera of his family elachistidae may probably be included in the gelechidae, but there will still remain many of the others which are difficult of location, unless each of them shall itself be held of family rather than of generic value. Thus Tischeria seems to me especially to stand alone. $\mathrm{Mr}$. Stainton places it in elachistidae; Dr. Clemens thought it belonged in lithocolletidae, an opinion in which I also was at one time inclined to cuncur, when looking only to some of the characters of the imago: but those of both larva and imago separate it to to coelo from lithocolletidae, and those of the larva separate it from all other lepidoptera: its labrum and maxillae are as much like those of some coleoptera. Cemiostoma also is suigeneris or rather suifamiliae. Mr. Grote rightly attaches much importance to the neuration of the wings, but, judged by this test, Cemiostoma seems to me to stand, if not alone, at least in no close relationship to any other genus. Our American species, C. albella, even differs from the European C. laburnella, as figured by Mr. Stainton in Insecta Britannica, v. 3 , in that albella has the median vein of the primaries furcate at the base, as well as in other minor respects. The pupae are in some respects singular, and in the larva the structure of the trophi is as distinct and unique as it is in Tischeria. Mr. Stainton places Cemiostoma in his family lyonetidae, along with Bucculatrix (the affinities of which are rather with Nepticula) and Phyllocnistis (which I think belongs with Coriscium and Lithocolletis). In the same family he places Lyonetia and Opostega, the affinities of which are yet doubtful, the latter probably belonging near Phyllocnistis. It seems to me that this family (lyonetidae) cannot stand; and there still remain, especially among the lower genera of elachistidae, many forms as to the proper location of which I am not able to form an opinion. But with what sort of consistency and upon what scientific principles all of these multitudes of such diverse structure, metamorphosis, lifehistory, habitat, form and ornamentation, can be thrown into a single group, the equivalent of a single family of the higher heterocera, I cannot comprehend; but it seems to me - with the greatest deference for such authorities as Lord Walsingham and Mr. Grotethat in all of the particulars just enumerated, the insects associated by them under the common family name tineidae present family characters in variety as great as or even greater than all other heterocera combined.

Like Mr. Grote I do not desire any controversy on this subject, and have written above all that I desire to say or shall say upon it, and here take my farewell of it, hoping that nothing I have written will be considered to be in the least degree wanting in respect to either of the distinguished gentlemen abovenamed. 

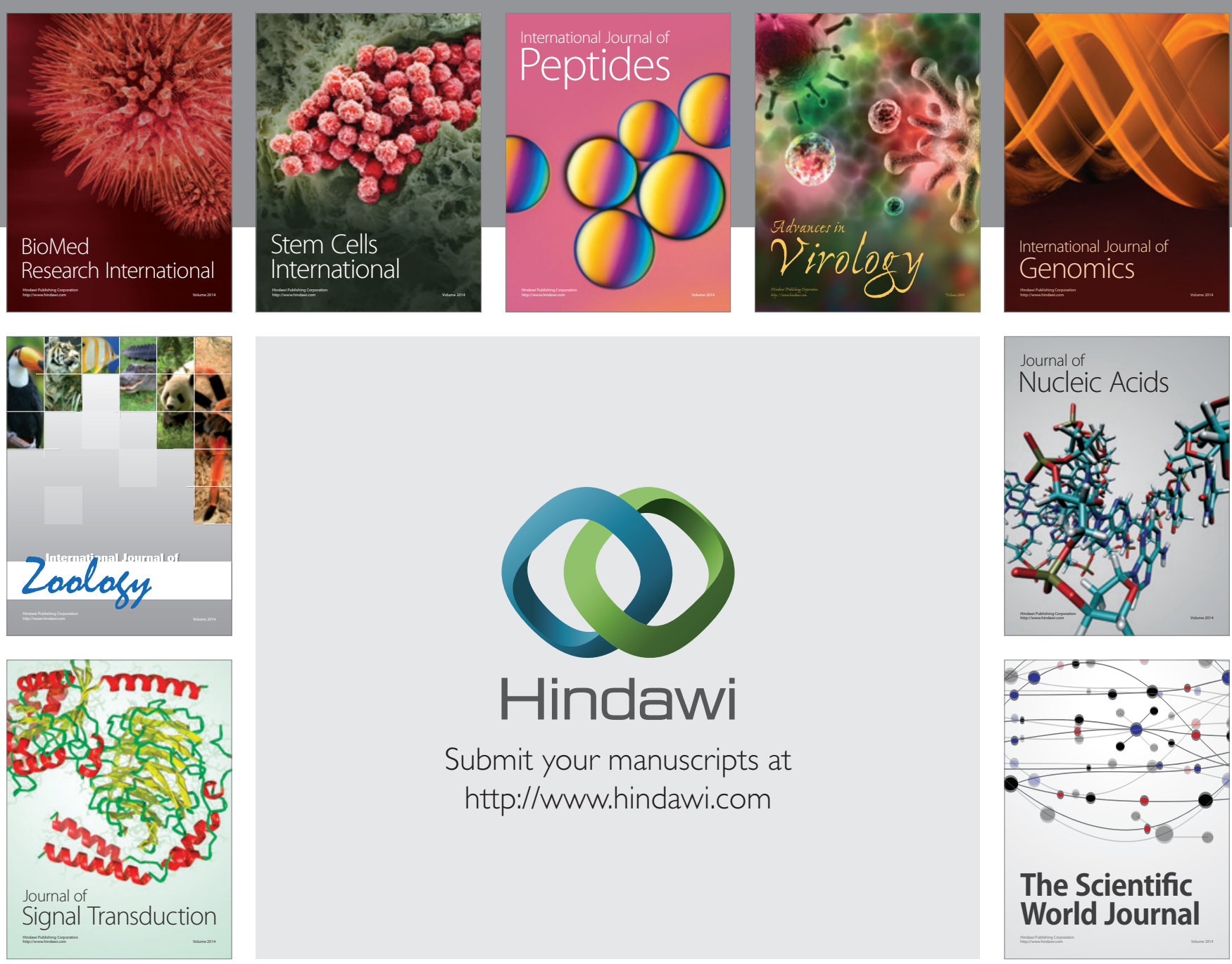

Submit your manuscripts at

http://www.hindawi.com
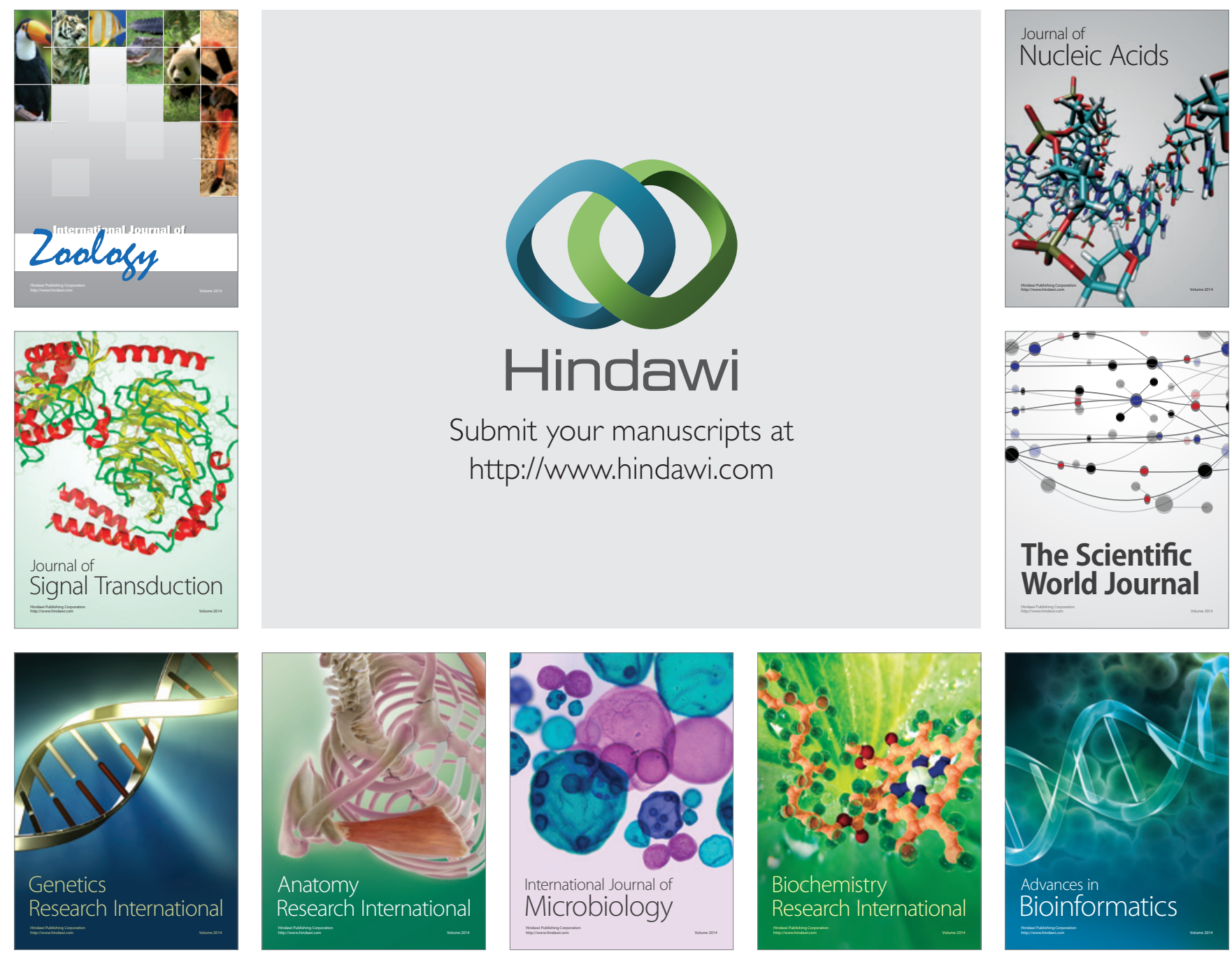

The Scientific World Journal
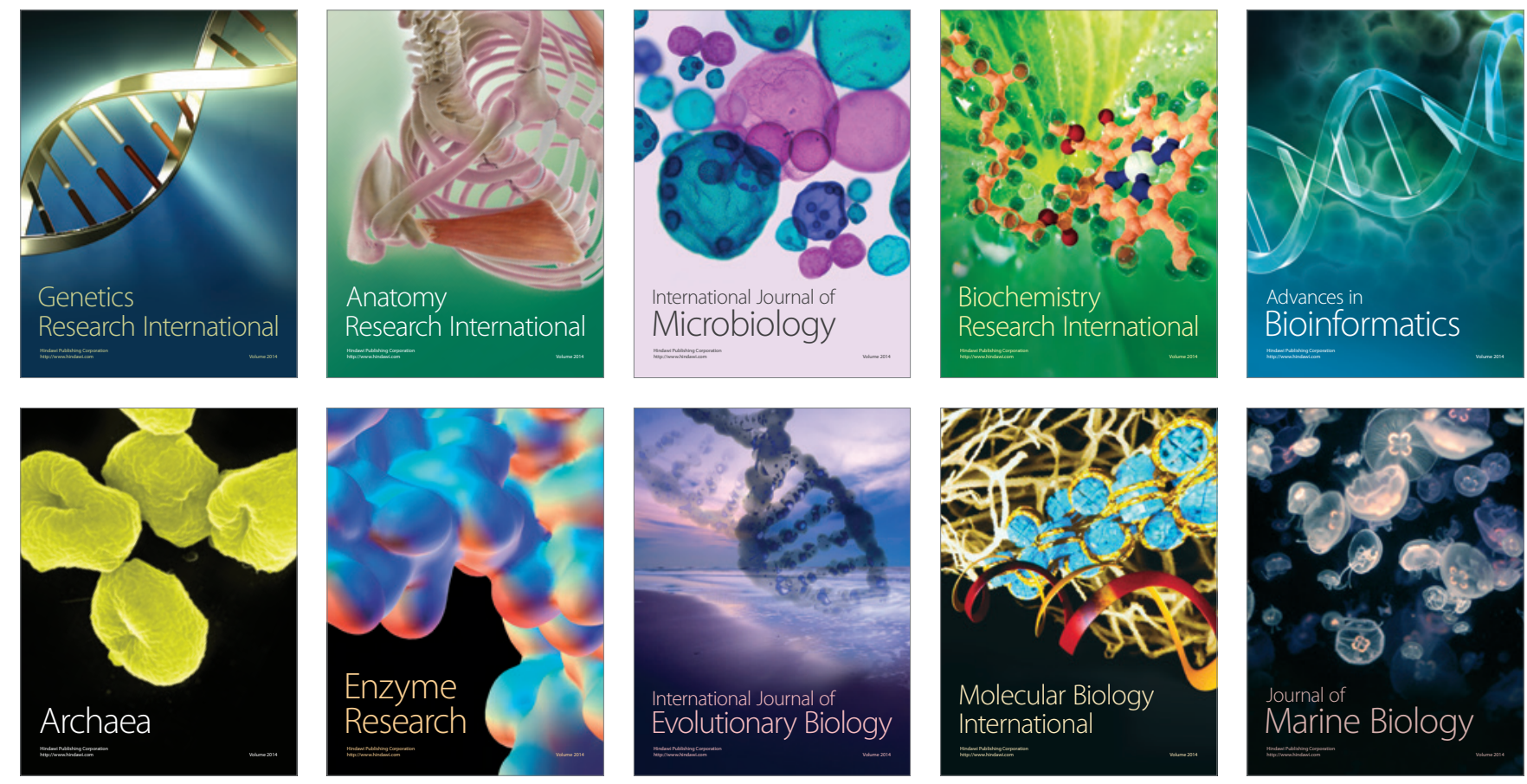